\title{
Improving the knowledge of clinical forensic medicine among medical graduates: Perspectives of community-service doctors
}

\author{
L Fouché, MB ChB, MMed (Med Forens), FC For Path (SA), PhD (HPE); J Bezuidenhout, BA (Ed), MEd, DTech (Ed), PGD (HPE); \\ A O Adefuye, MB ChB, MSc (Microbiol), $\mathrm{PhD}$ (Med Biochem)
}

Division Health Sciences Education, Office of the Dean, Faculty of Health Sciences, University of the Free State, Bloemfontein, South Africa

Corresponding author: A O Adefuye (adefuyeao@ufs.ac.za)

\begin{abstract}
Background. Teaching and learning of clinical forensic medicine (CFM) in the undergraduate medical curriculum is declining, which results in deficient handling of medicolegal cases by doctors. We previously demonstrated that some community-service doctors (CSDs) lack the required competence to assess and document medicolegal cases involving rape/sexual assault, inebriated drivers and common physical assault.

Objective. To obtain the perspectives of CSDs on how medical graduates' knowledge of CFM can be improved.

Methods. This was a descriptive study using a questionnaire survey to gather qualitative data from 150 CSDs.

Results. Analysis of the comments of the CSDs revealed three core themes, i.e. training, practical work and exposure.

Conclusions. South African courts rely heavily on medicolegal evidence for successful prosecution of physical assault, rape/sexual assault or drunk driving cases. The inept handling, collecting and processing of medicolegal evidence by healthcare providers have been attributed to lack of rigorous training and poor performance standards. It is important that healthcare providers are trained and competent, and possess the skills required to collect evidence and document medicolegal findings correctly.
\end{abstract}

Afr J Health Professions Educ 2019;11(3):81-82. https://doi.org/10.7196/AJHPE.2019.v11i3.1171

Since the beginning of mankind there has been a need for clinical forensic medical services: 'Cain overpowered Abel and killed him' (Genesis 4:8, New International Version Bible). Clinical forensic medicine (CFM) applies knowledge from all specialties of medicine for the administration of justice in courts of law, ${ }^{[1,2]}$ thereby acting as a link between medical practice and the law. Because all practising physicians, regardless of specialty, are often required to evaluate CFM cases, increasing scrutiny by the judicial system demands that medical graduates/students undergo satisfactory training in CFM and are informed regarding the consequences of their practices, not only on health, but also in the legal, social and economic domains, as the consequences relate to the rights and quality of life of their patients. ${ }^{[3]}$

We previously demonstrated that some community service doctors (CSDs) lack the required competence to assess and document medicolegal findings relating to rape/sexual assault, ${ }^{[4]}$ inebriated drivers, ${ }^{[5]}$ and common physical assault. ${ }^{[6]}$ These findings revealed a consequential gap in the cognisance and adeptness of medical graduates regarding the practice of clinical forensics, and the necessity for a revised curriculum for CFM to address the inadequacies of undergraduate medical training programmes. We present the perspectives of the abovementioned CSDs on how knowledge of medical graduates of CFM can be improved.

\section{Methods}

This research was designed as a descriptive study that made use of a questionnaire survey to gather qualitative data from 150 CSDs.

\section{Instrument}

Data were collected using a structured, self-administered questionnaire distributed electronically to participants via the EvaSys electronic survey system (Electric Paper, Germany). It comprised open-ended questions that allowed participants to suggest how medical graduates' knowledge of CFM can be increased.

\section{Ethical approval}

This study was approved by the Health Sciences Research Ethics Committee, Faculty of Health Sciences, University of the Free State, Bloemfontein, South Africa (SA) (ref. no. HSREC 149/2011).

\section{Data analysis}

Responses to the open questions were read and re-read by the investigators to familiarise themselves with the content. Content analysis was done using NVivo 12 software (QSR International Pty Ltd, Australia). Thematic analysis formed the cornerstone of the analysis, with emphasis on patterns and emerging themes.

\section{Results}

Analysis of the comments of the CSDs revealed three core themes, i.e. training, practical work and exposure. Each theme is supported by CSDs responses quoted verbatim.

\section{Training}

CSDs indicated that providing more training opportunities at undergraduate level is key to improving medical graduates' knowledge of CFM:

'More undergraduate training and exposure.'

'I think there should be more training for an undergraduate on the legal implications for the examiner.'

'Undergraduates should rotate and be on call with the district physician in medicolegal departments.' 
One major component of CFM is the detailed assessment/examination, documentation and treatment of patients who report having been physically or sexually assaulted or raped. ${ }^{[4]}$ Known as medicolegal examinations, they entail a very detailed history regarding the incident, and a thorough general examination coupled with collection of forensic samples. ${ }^{[4]}$ Therefore, CSDs in this study suggested that training should focus more on aspects of history taking, examination, completing the appropriate form (J88) and documentation, and how to use the required kits to collect forensic evidence:

'Restructuring the medical training to include examining and appropriate history taking and correctly filling in documentation as part of undergraduate education would be a step in the right direction.

'... also training in filling in the documents correctly .... '

'Training on how to complete J88 forms.'

'Training with the actual kits.'

\section{Practical work}

According to the CSDs, theoretical teaching of CFM is inadequate for impacting knowledge. Therefore, they advocated that training should be made more practical:

'One lecture is not enough ... theoretical lectures are not sufficient. I think it needs to be shown to students practically.

'Combine theoretical knowledge with practical exposure.'

'... thus I would suggest more practical exposure be given to students .... ' 'Getting practical experience would help.'

\section{Exposure}

The third core theme was exposure. Here, CSDs suggested that undergraduate students should be exposed to real-life cases, as this would make training more meaningful:

'Proper exposure to cases, especially assault cases; wound examinations with an experienced clinician on a regular basis.'

'More practical exposure to different case studies.'

'To increase exposure to case studies and increase the time period spent on forensics.

\section{Discussion}

The training of undergraduate $\mathrm{MB} \mathrm{ChB}$ students in $\mathrm{CFM}$ is a prerequisite set by the subcommittee for Undergraduate Education and Training of the Medical and Dental Professions Board in SA. ${ }^{[7]}$ However, teaching and learning of CFM in the undergraduate medical curriculum has been declining, which has resulted in deficient handling of medicolegal cases by doctors. ${ }^{[8,9]}$ In this study, CSDs claim that more teaching/training opportunities are required in the undergraduate medical curriculum to improve medical graduates' knowledge of CFM. Furthermore, CSDs indicated that training should be made more practical and meaningful by exposing students to real-life cases. This suggestion is very important, as traditional methods of teaching (i.e. didactic lectures with few demonstrations) have resulted in impaired student learning and poor skills acquisition. ${ }^{[10]}$

SA courts rely heavily on medicolegal evidence for successful prosecution of physical assault, rape/sexual assault or drunk-driving cases. The inept handling, collecting and processing of medicolegal evidence by healthcare providers have been attributed to lack of rigorous training and poor performance standards. ${ }^{[11]}$ Therefore, it is important that healthcare providers are trained and competent, and possess the skills needed to collect evidence and document medicolegal findings properly.

\section{Study limitations and future research}

The CSDs who participated in this study were graduates of a single medical institution, which could limit the generalisability of this study. Further research could investigate the perspectives of other CSDs (graduates of other medical institutions) to obtain views from a representative population. Furthermore, studies can be conducted to develop a curriculum framework for teaching CFM in undergraduate medical education.

\section{Declaration. None.}

Acknowledgements. The Health and Welfare Sector Education and Training Authority (HWSETA)

Author contributions. LF conceptualised the study and collated the data; JB conceptualised the study and reviewed the manuscript; AOA collated and analysed the data and wrote the manuscript.

Funding. None.

Conflicts of interest. None.

Reddy NKS. The Essentials of Forensic Medicine and Toxicology. Mumbai: Jaypee Brothers Medical Publishers, 2014.

2. Madea B, Saukko P. Future in forensic medicine as an academic discipline - focussing on research. Forensic Sci Int 2007;165(2-3):87-91. https://doi.org/10.1016/j.forsciint.2006.05.030

3. Magalhães T, Dinis-Oliveira RJ, Santos A. Teaching forensic medicine in the University of Porto. J Forensic Leg Med 2014;25:45-48. https://doi.org/10.1016/j.jflm.2014.04.011

4. Fouché L, Bezuidenhout J, Liebenberg C, Adefuye A. Medico-legal documentation of rape or sexual assault: Are community-service doctors equipped for the task? S Afr Fam Pract 2018;60(1):8-12. https://doi.org/10.1080/20 786190.2017 .1348046

5. Fouché L, Bezuidenhout J, Liebenberg C, Adefuye A. Medico-legal aspects regarding drunk driving: Experience and competency in practice of community service doctors. S Afr Fam Pract 2018;60(2):63-69. https://doi.org/1 $0.1080 / 20786190.2017 .1386899$

6. Fouché L, Bezuidenhout J, Liebenberg C, Adefuye A. Practice of community-service doctors in the assessment and medico-legal documentation of common physical assault cases. S Afr Fam Pract 2018;60(1):21-25. https:// and medico-legal documentation of con

7. Kotzé JM, Brits H, Botes B. Part 1: Medico-legal documentation South African Police Services forms, Department Kotze JM, Brits H, Botes B. Part 1: Medico-legal documentation South African
of Justice forms and patient information. S Afr Fam Pract 2014;56(5):16-22.

of Justice forms and patient information. S Afr Fam Pract 2014;56(5):16-22.
8. Jones RM. Getting to the core of medicine: Developing undergraduate forensic medicine and pathology teaching 8. Jones RM. Getting to the core of medicine: Developing undergraduate forensic me
J Forensic Leg Med 2017;52:245-251. https://doi.org/10.1016/j.jflm.2017.10.006

9. Murty O. Modular teaching in forensic medicine and toxicology. J Forensic Med Toxicol 2012;29(1):1-17.

10. Gupta S, Parekh UN, Ganjiwale JD. Student's perception about innovative teaching learning practices in forensic medicine. J Forensic Leg Med 2017;52:137-142. https://doi.org/10.1016/j.jflm.2017.09.007

11. Du Mont J, White D. Seeking a better world for women and girls. BMJ 2011;343:d5712. https://doi.org/10.1136/ bmj.d5712

Accepted 7 March 2019 